\title{
Desenvolvimento de uma máquina para ensaio de fadiga por flexão
}

\author{
Development of a bending fatigue \\ testing machine
}

Matheus da Silva Lages ${ }^{1}$, Alexandre Mendes Abrão ${ }^{1}$, Anderson Júnior dos Santos ${ }^{1}$, Marcelo Araújo Câmara ${ }^{1}$

\footnotetext{
${ }^{1}$ Departamento de Engenharia Mecânica - Universidade Federal de Minas Gerais - Av Antônio Carlos, 6627, CEP: 31270901, Belo Horizonte, Minas Gerais, Brasil.

e-mail: matheuslages@yahoo.com.br, abrao@demec.ufmg.br, ndersonsantos@hotmail.com, marcelocamara@demec.ufmg.br
}

\section{RESUMO}

O conhecimento acerca das propriedades mecânicas dos materiais é de grande importância para aplicações de engenharia. $\mathrm{O}$ estudo dessas propriedades é necessário para o desenvolvimento de novos equipamentos ou produtos e uma importante propriedade é a resistência à fadiga. O objetivo deste trabalho é apresentar o projeto e construção de uma máquina para ensaio de fadiga por flexão. O projeto da máquina foi dividido em subconjuntos distintos denominados estrutural, dinâmico e de controle e coleta de dados, sendo cada subconjunto formado por peças e acessórios necessários para a realização dos ensaios de fadiga. Neste contexto, merece destaque a concepção de um novo sistema que permite a variação da tensão aplicada durante o ensaio, o qual é mais simples e não menos eficiente em comparação àqueles tradicionalmente utilizados em máquinas comerciais do mesmo porte. Ensaios preliminares foram realizados utilizando corpos de prova de aço ABNT 1020 no estado recozido e os resultados indicaram que a máquina apresenta desempenho satisfatório, pois foi possível a realização dos testes, o registro dos resultados e a consequente obtenção de dados confiáveis para elaboração da curva de Wöhler.

Palavras-chave: Ensaio de fadiga por flexão, fadiga, projeto de máquina, curva de Wöhler.

\section{ABSTRACT}

Knowledge regarding properties of materials is of utmost importance for engineering applications. The study of these properties is crucial for the development of new equipment or products and an important property is the fatigue resistance of materials. The goal of this work is to design and build a fatigue machine for bending tests. Machine design has been split in different groups, namely structural, dynamic and control and data acquisition, each of them consisting of parts and accessories required to perform fatigue tests. A novel system for variation of the applied stress was developed, which is simpler and as effective as those traditionally used in commercial machines. Validation tests were performed using annealed AISI 1020 steel specimens and indicated that the machine presents satisfactory performance, thus allowing the generation of reliable data for plotting Wöhler curve.

Keywords: Bending fatigue test, fatigue, machine design, Wöhler curve.

\section{INTRODUÇÃO}

Segundo CALLISTER [1], existem três grupos principais de materiais, os quais são classificados como: metais, polímeros e cerâmicos e são diferenciados pela sua composição atômica e química. Cada grupo possui diversos compostos com propriedades mecânicas individuais, o que leva um material a ser aplicável em uma situação ou não [2, 3]. Entre as diversas propriedades dos materiais, destaca-se a resistência à fadiga.

A fadiga é uma propriedade mecânica que pode ser definida como um processo de danos localizados em peças e componentes sujeitos a esforços cíclicos [4,5]. As falhas por fadiga ocorrem em componentes estruturais e dinâmicos que estão sujeitos a esforços cíclicos cujos valores são inferiores ao limite de escoa- 
mento do material [6], sendo responsável pela maioria das falhas mecânicas em máquinas e equipamento (50 a $90 \%$ ), acontecendo majoritariamente de forma repentina [7]. Falhas por fadiga é um processo de acúmulo de cargas localizadas devido às cargas cíclicas, sendo caracterização pela formação e propagação de uma trinca, até o rompimento do material $[8,9]$.

A avaliação da resistência à fadiga de um material pode ser realizada por intermédio do estudo de gráficos de tensão aplicada ( $\sigma$ ou $\mathrm{S}$ ) em função do número de ciclos $(\mathrm{N})$ necessários para fraturar o material. A realização de diversos ensaios utilizando o mesmo material sob diferentes tensões e, consequentemente, diferentes números de ciclos até a fratura, resulta em um gráfico de vida em fadiga que apresenta uma curva $\mathrm{S}-\mathrm{N}$, denominada curva de Wöhler [10,11]. A curva S-N (Figura 1) permite realizar uma previsão do número de ciclos de vida em fadiga de um material baseado nos esforços mecânicos aos quais ele está submetido. Quanto maior for a tensão aplicada, menor o número de ciclos necessários para levar o material à fratura por fadiga. O número de ciclos sob o qual o material irá falhar é especificado como resistência à fadiga e varia de um material para outro. É importante observar que nem todos os materiais possuem a propriedade de resistência à fadiga [1].

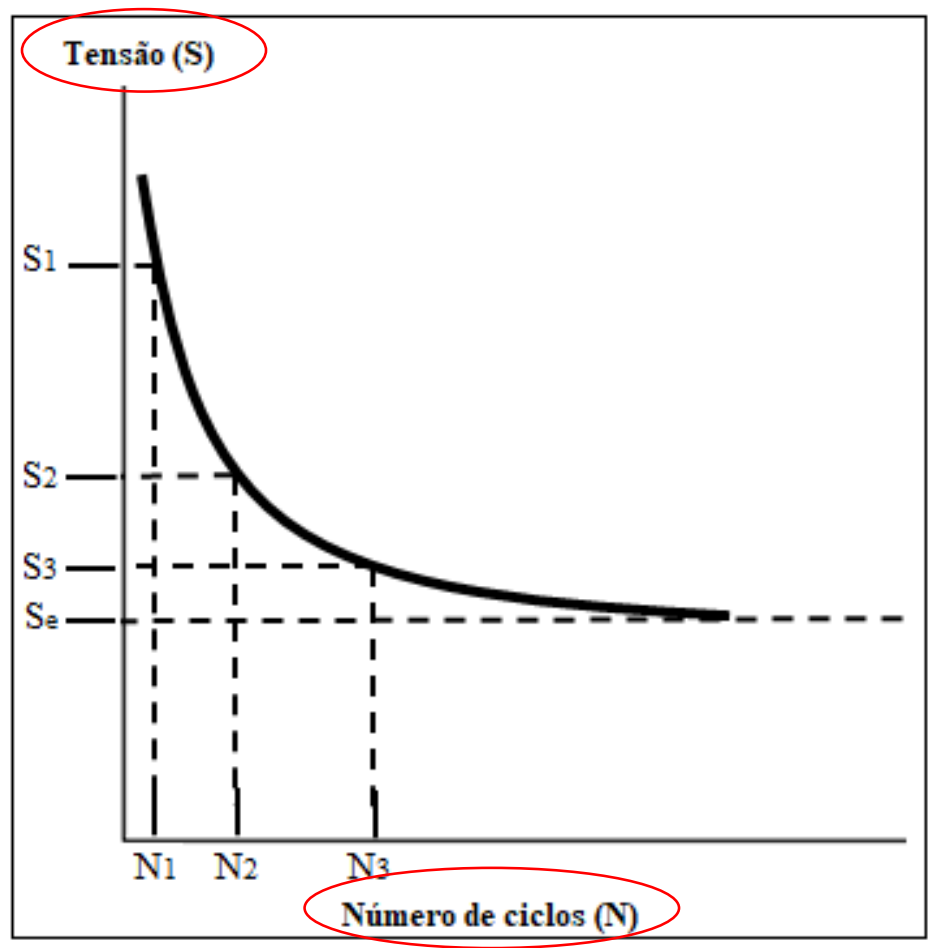

Figura 1: Representação de uma curva S-N típica.

Um método para fornecer resultados dos ensaios de fadiga com menor dispersão é conhecido como método de "Staircase" ou "up-and-down". O método consiste na determinação da vida de fadiga de interesse, assumindo que após esse valor o material não falhará mais por fadiga. Cada nível de tensão escolhido para os testes é baseado no resultado do teste anterior de modo que: se o corpo de prova não falhou para um número de ciclos pré-determinado, deve-se realizar o próximo teste com um nível de tensão maior. Caso o corpo de prova falhe antes de atingir a vida de interesse, o nível de tensão do próximo ensaio deve ser reduzido. Para o emprego deste método, recomenda-se o uso de pelo menos 15 corpos de prova [4].

Os ensaios para obtenção da curva S-N de um material geralmente são realizados em laboratório. Diferentes tipos de cargas, amostras, ambientes e equipamentos são utilizados nos testes [12]. Segundo MILELLA [13], Os ensaios de fadiga são definidos pela aplicação de uma carga cíclica em um corpo de prova até o rompimento deste, podendo ser agrupados em quatro tipos básicos que dependem da aplicação da carga e do processo do ensaio: flexão alternada, flexão rotativa, tração-compressão e torção.

O ensaio de fadiga por flexão alternada é caracterizado pela aplicação de uma força em uma das extremidades do corpo de prova que realiza movimentos alternativos, enquanto a outra extremidade permanece fixa (Figura 2). Neste tipo de ensaio, o corpo de prova possui superfície trapezoidal. A utilização de superfícies cônicas garante que o estado de tensões seja constante independentemente da distância da aplicação da 
força [14]. Diferentes espessuras e tamanhos de corpos de prova podem ser utilizados, entretanto, quanto maior a espessura do corpo de prova para um mesmo comprimento, maior a força que a máquina aplicará na extremidade móvel para manter um mesmo estado de tensão [14].

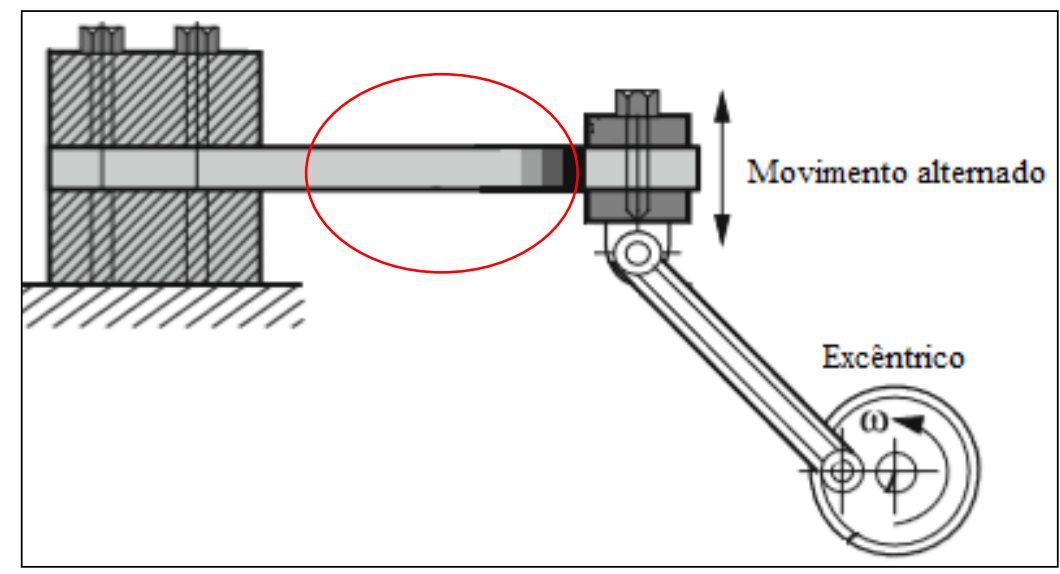

Figura 2: Representação de um ensaio de fadiga por flexão.

Devido à importância do processo de fadiga nos materiais, diferentes estudos são realizados para melhor entender este fenômeno. Um dos estudos relaciona-se a estimar dos danos ocasionados pela fadiga nos materiais, podendo ser previsto por modelos. que possuem boa aproximação com o resultado encontrado na prática. GAUTAM et al. [15], por exemplo, conflitou a estimativa do dano por fadiga para o aço ABNT 1020 previsto pelo modelo de Yang et al. com resultados práticos e constatou que os resultados de ambos são semelhantes, comprovando a boa aproximação fornecida pelo modelo. Outros estudos são voltados para a rugosidade da superfície. LACERDA et al. [16] relacionou em seu trabalho a rugosidade superficial da fratura por fadiga do aço ABNT 1020 com diferentes cargas cíclicas de fadiga e constatou que a rugosidade média por si só não pode ser considerada como um indicador para prever a falha por fadiga. Procurando entender melhor o desenvolvimento das trincas superficiais causadas pelas tensões cíclicas, HAGHSHENAS e KHONSARI [17] em seu trabalho procuraram relacionar a inicialização de trincas que causam fratura por fadiga com o desenvolvimento da rugosidade superficial nesses materiais.

As máquinas para a realização de ensaios de fadiga devem ser construídas de acordo com o ensaio proposto, isto é, devem reproduzir de forma fidedigna os esforços aos quais o material será submetido. O projeto de qualquer máquina ou equipamento deve levar em consideração diversos pontos como a seleção correta dos materiais, processos de fabricação, custo, condição de serviço, recursos, entre outros [18]. Entretanto, uma vez construída, a máquina é útil para diversas pesquisas, incluindo desenvolvimento de novos produtos e aperfeiçoamento dos já existentes. Este trabalho tem como objetivo principal o projeto e construção de uma máquina para ensaio de fadiga por flexão. Além disso, propõe um novo sistema de variação da tensão aplicada durante cada ensaio, o qual é construtivamente mais simples e tão eficiente quanto os sistemas tradicionalmente usados em máquinas de fadiga comerciais do mesmo porte.

\section{MATERIAIS E MÉTODOS}

\subsection{Princípio básico do equipamento}

Durante a realização do ensaio de fadiga por flexão, o corpo de prova deve ter suas extremidades fixas à máquina por meio de garras, de modo que uma extremidade permaneça imóvel enquanto a outra realiza movimentos alternados de flexão (extremidade móvel). Para isso, a extremidade móvel deve ser acoplada aos elementos ligados à biela. $\mathrm{O}$ movimento circular do eixo é transformado em retilíneo pela biela, de modo que cada revolução corresponde a um ciclo alternado no movimento vertical da biela. Essa movimentação retilínea é transmitida ao corpo de prova e a repetição dos ciclos deve ocorrer até o rompimento do material, finalizando o ensaio. A partir do princípio básico, o projeto da máquina foi desmembrado em subconjuntos para facilitar a construção, o entendimento e a necessidade de cada elemento utilizado. Os três subconjuntos utilizados, estrutural, dinâmico e de controle e coleta de dados, possuem funções distintas, entretanto, trabalham 
em harmonia para que seja possível a realização dos ensaios de fadiga [18].

\subsection{Subconjunto Estrutural}

O subconjunto estrutural é composto por elementos utilizados na estrutura da máquina, fornecendo resistência mecânica e estabilidade apropriadas para que a máquina suporte os esforços solicitados durante os ensaios sem interferir nos resultados coletados. Além disso, a estrutura da máquina deve permitir que os demais elementos necessários para a realização dos ensaios sejam montados [18]. A Figura 3 representa o modelamento do subconjunto estrutural com suas peças e acessórios. O subconjunto estrutural é composto por três tampas e um bloco chamado conjunto fixador na região superior, paredes e estruturas de apoio dos elementos do subconjunto dinâmico na região intermediária e pés associados a coxins de borracha na região inferior.

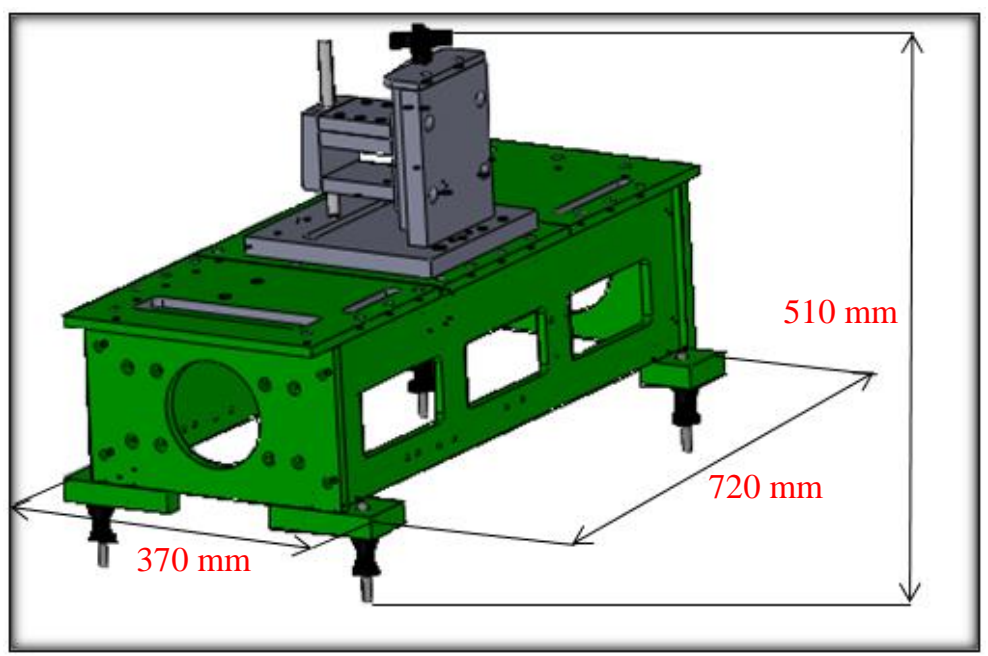

Figura 3: Representação da estrutura da máquina de fadiga e suas dimensões externas.

\subsection{Subconjunto Dinâmico}

O subconjunto dinâmico representado na Figura 4 é responsável por fornecer o torque necessário à realização dos ensaios de fadiga e, para isso, componentes e acessórios devem atuar de modo sincronizado a fim de fornecer aos corpos de prova esforços cíclicos alternativos até sua ruptura [18]. As peças que fazem parte do subconjunto dinâmico são: motor e inversor de frequência, sistema de redução, conjunto biela-base móvel e acessórios. O motor fornece torque e como deseja-se que a máquina realize ensaios de fadiga por meio de movimento retilíneo, componentes intermediários devem ser acrescentados entre o motor e o corpo de prova.

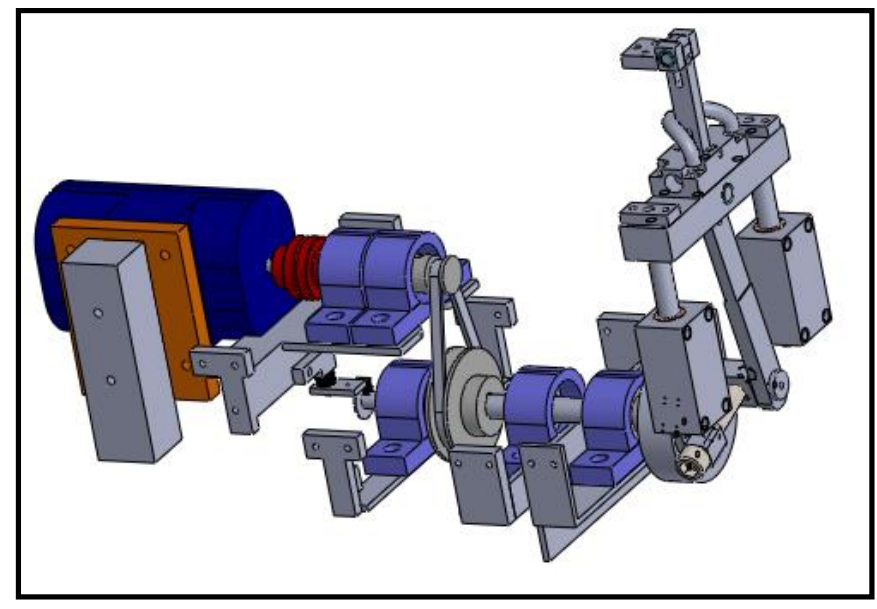

Figura 4: Subconjunto dinâmico com as peças estruturais de fixação.

O motor elétrico utilizado foi selecionado por ser considerado de alta eficiência, baixo custo e robusto. 
Associado ao motor foi utilizado um inversor de frequência que controla a velocidade dos ensaios por meio do controle da rotação do motor e também é utilizado como chave de segurança, desarmando o motor em caso de sobrecarga. O torque máximo disponibilizado pelo motor é de $0,3 \mathrm{kgfm}$, o que pode limitar os ensaios uma vez que a tensão aplicada durante a realização dos ensaios é influenciada diretamente pela amplitude de flecha e pelas características dos materiais utilizados na confecção dos corpos de prova. Para aumentar a faixa de ensaios possível, uma redução de 3:1 foi utilizada para aumentar o torque disponibilizado pelo motor para $0,9 \mathrm{kgfm}$ (ignorando perdas). A redução foi obtida por meio da utilização de duas polias em $\mathrm{V}$ de alumínio, uma delas $(\varnothing 30 \mathrm{~mm})$ ligada ao eixo motor (polia motora) e outra polia ( $\varnothing 90 \mathrm{~mm}$ ) ligada ao eixo secundário (polia movida). A transmissão de rotação e torque da polia motora para a movida é realizada por meio de uma correia.

O movimento circular fornecido pelo motor elétrico deve ser transformado em movimento retilíneo para que o ensaio de fadiga por flexão seja possível. Para possibilitar essa transformação, foi utilizado um conjunto chamado de biela-base móvel (Figura 5).

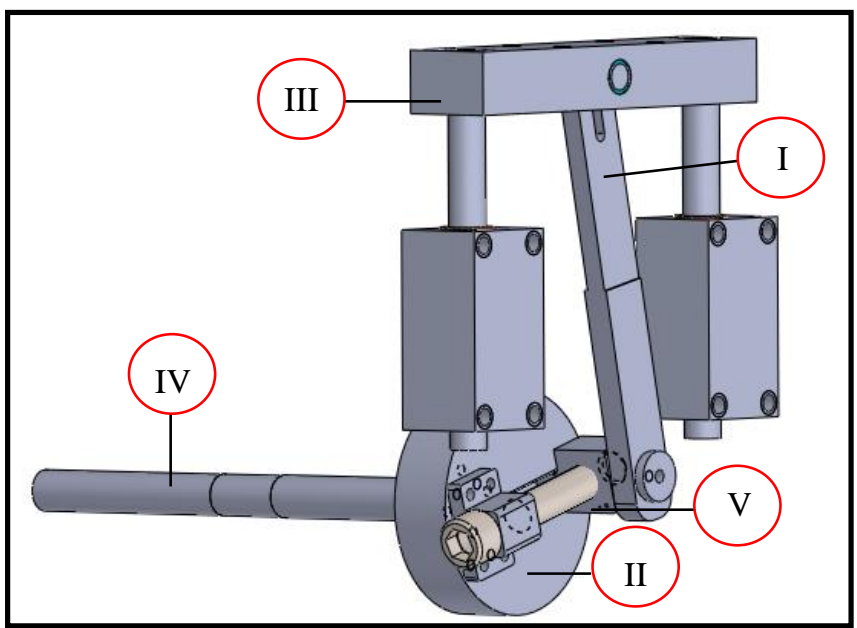

Figura 5: Mecanismo responsável por transformar movimento circular em vertical.

O conjunto biela-base móvel assemelha-se aos mecanismos biela-manivela encontrados em diferentes máquinas que necessitam realizar a conversão de movimento circular para retilíneo ou vice-versa. No mecanismo representado na Figura 5, a biela (I) é conectada em suas extremidades ao volante (II) e à base móvel (III) por pinos. O movimento circular do eixo secundário (IV) é transmitido para a biela, que realiza a transformação para movimento retilíneo na base móvel. O movimento retilíneo resultante é possibilitado pelo auxílio de eixos guias, mancais e buchas que direcionam e mantém e perfeito alinhamento no movimento base móvel. A máquina de fadiga por flexão deve permitir que a amplitude da flecha responsável pela deformação do corpo de prova seja variável de modo que o ensaio ocorra com um valor de flecha determinado previamente pelo usuário. A variação da flecha é possível por meio da variação da posição do pino utilizado para conectar a biela ao volante (V), de modo que o pino possa ser fixado livremente em relação a um excêntrico. Tal solução não é encontrada em máquinas comerciais para ensaio de fadiga, as quais normalmente utilizam sistemas de cames para possibilitar a variação da amplitude da flecha [18].

A amplitude do movimento dependerá da localização do pino sobre o volante, de modo que quanto mais próximo à extremidade do bloco, maior será a amplitude da flecha [18]. Pode-se relacionar a distância do pino até o centro do volante com a amplitude da flecha de maneira que o valor da amplitude seja o dobro da distância do pino até o centro do volante, ou seja, pode-se determinar a amplitude de ensaio sabendo a localização do pino sobre o volante. O valor máximo de amplitude acontece quando o pino está localizado na posição mais extrema do excêntrico. A posição mais externa que o pino pode ser posicionado é de 41,5 mm do centro do excêntrico, que representa uma amplitude de flecha de $83 \mathrm{~mm}$.

Para ser possível a movimentação do pino sobre o volante, foi usinado um canal na peça e o pino teve sua base adaptada para possibilitar a movimentação. Um parafuso com cabeça sextavada foi utilizado para realizar a movimentação e travamento do pino. Para isso, o parafuso foi fixado ao volante não permitindo seu movimento no sentido horizontal ou vertical em relação ao volante, apenas o movimento rotacional. A base do pino foi rosqueada de modo que quando o parafuso é girado no sentido horário, o pino se desloca para o centro do volante e, quando o parafuso é girado no sentido anti-horário, o pino se desloca para a extremidade 
do bloco. A realização do movimento rotacional do bloco, o deslocamento em apenas um sentido da base móvel e a transição do movimento circular para movimento retilíneo possibilitado pela biela somente são possíveis com a utilização de mancais, buchas, eixos guias, rolamentos e outros pinos.

Três peças mecânicas com alguns acessórios foram utilizadas para possibilitar que a flecha disponibilizada pelo mecanismo descrito possa ser transferida para o corpo de prova para a realização do ensaio (Figura 6): uma haste (I), a base da haste (II) e o fixador móvel (III). A base da haste é fixada à base móvel, recebendo o movimento vertical. A base móvel transmite esse movimento para a haste e para a peça denominada fixador móvel. A extremidade móvel do corpo de prova é fixada no fixador móvel com o auxílio de três parafusos. Desta maneira, o movimento vertical da base móvel é transferido para a extremidade do corpo de prova parafusado nele. Outros componentes são utilizados para permitir a correta movimentação das peças e fixação das mesmas, como rolamentos e duas peças auxiliares (IV) utilizadas para fixar os eixos guias (V) à base móvel.

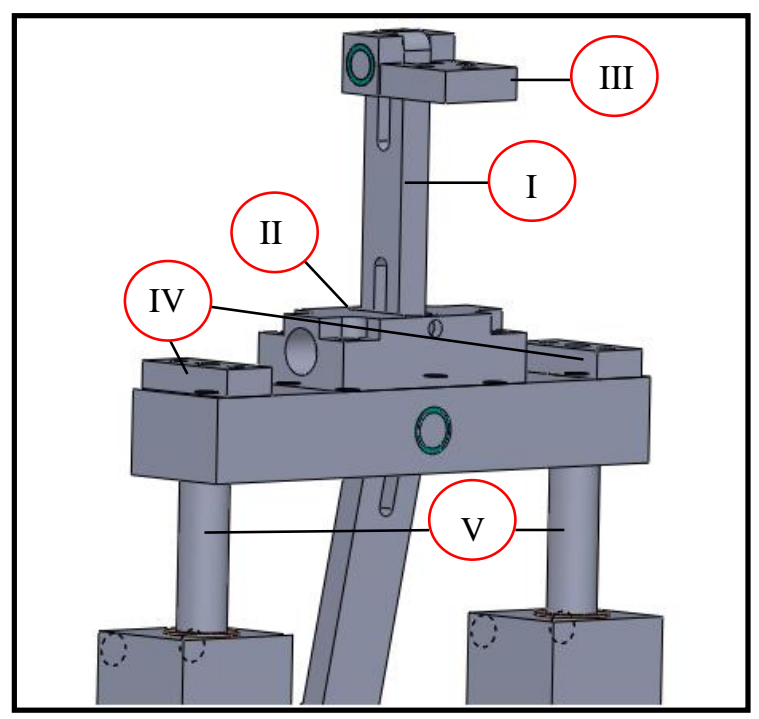

Figura 6: Mecanismo responsável por transmitir a flecha para o corpo de prova.

Para transmitir o torque do motor para o sistema dinâmico, foi utilizado um acoplamento flexível. Este tipo de acoplamento foi selecionado por atender aos requisitos da máquina, absorvendo as vibrações do sistema e por tolerar certo nível de desalinhamento entre o eixo e o motor.

O uso de mancais de deslizamento e de rolamento foi necessário em diferentes pontos da máquina. Os mancais utilizados são encontrados comercialmente e os eixos e pinos foram projetados e fabricados com dimensões que atendem tanto aos esforços solicitados quanto às dimensões encontradas comercialmente dos mancais. Apenas dois mancais utilizados como guias para a parte móvel não são encontrados comercialmente e foram fabricados exclusivamente para esta aplicação.

\subsection{Subconjunto de controle e coleta de dados}

A parte mecânica é fundamental para que o teste seja executado, entretanto, também é necessária a inclusão de elementos eletrônicos que realizem a coleta e armazenamento dos resultados de cada ensaio. Para isso, um sistema eletrônico foi utilizado para contabilizar o número de ciclos ao qual o corpo de prova é submetido até a sua ruptura.

O ensaio de fadiga acusa o número de ciclos necessários para que um material frature sob determinada tensão e para a realização da contagem foi utilizado um sensor associado a um encoder. O sensor utilizado foi o Fairchild H22A, que contabiliza o número de rotações do eixo secundário e, consequentemente, a quantidade de ciclos de flexão de cada ensaio. O sensor possibilita a leitura do número de ciclos através da emissão de um feixe infravermelho do emissor para o detector, onde fototransistores detectam a radiação. O conjunto conhecido como encoder é um disco com um rasgo radial que permite que o feixe infravermelho atinja os fototransistores apenas uma vez em cada ciclo do ensaio.

Como o número de ciclos está diretamente relacionado ao funcionamento operacional da máquina, é necessário que esta encerre suas atividades logo após a ruptura do corpo de prova, finalizando a contagem de ciclos. Para isso, um sensor de fim de curso foi posicionado em local estratégico para que o ensaio seja inter- 
rompido quando o corpo de prova fraturar. Quando ocorre a fratura, uma mola movimenta a haste móvel de encontro ao sensor, acionando-o e encerrando o ensaio. Quando acionado, o sensor de fim de curso envia um comando para a plataforma Arduino que finaliza a operação e encerra a contagem de ciclos.

A leitura das informações e aplicação de comandos para início e interrupção do funcionamento da máquina de fadiga é possível por meio da utilização de uma plataforma Arduino UNO, com programação em linguagem $\mathrm{C}++$. A programação foi elaborada de modo que antes de iniciar o funcionamento da máquina seja necessário colocar o número de ciclos de operação desejados, que pode variar de 0 a infinito, e somente após esta definição o motor pode ser acionado. Um display LCD com teclas foi utilizado para permitir que os dados de entrada sejam inseridos e que o número de ciclos seja apresentado em tempo real.

Um cartão de memória foi utilizado para registrar os dados de cada ensaio, garantindo que estes não se percam mesmo na ocorrência de falha ou pane elétrica. Cada ensaio é registrado no cartão de memória e os dados são apresentados em um relatório individual que fornece o horário em que o ensaio foi iniciado, a duração, os dados de entrada utilizados (números de ciclos selecionados) e se o encerramento do ensaio ocorreu devido ao acionamento do sensor fim de curso ou se o ensaio foi finalizado quando o número desejado de ciclos foi atingido.

\subsection{Dimensionamento, materiais, fabricação e montagem}

Definidos os subconjuntos com seus respectivos componentes necessários para que a máquina consiga realizar os ensaios de fadiga, realizou-se o dimensionamento das peças de cada subconjunto com o objetivo de se fazer a modelagem digital e verificar a ocorrência de erros de interferência ou de funcionamento. As peças foram modeladas individualmente e montadas de maneira a formar os subconjuntos citados anteriormente, que foram conectados entre si formando a máquina completa. O software Solidworks 2013 foi utilizado para a realização dos desenhos apresentados apresentado na Figura 7.

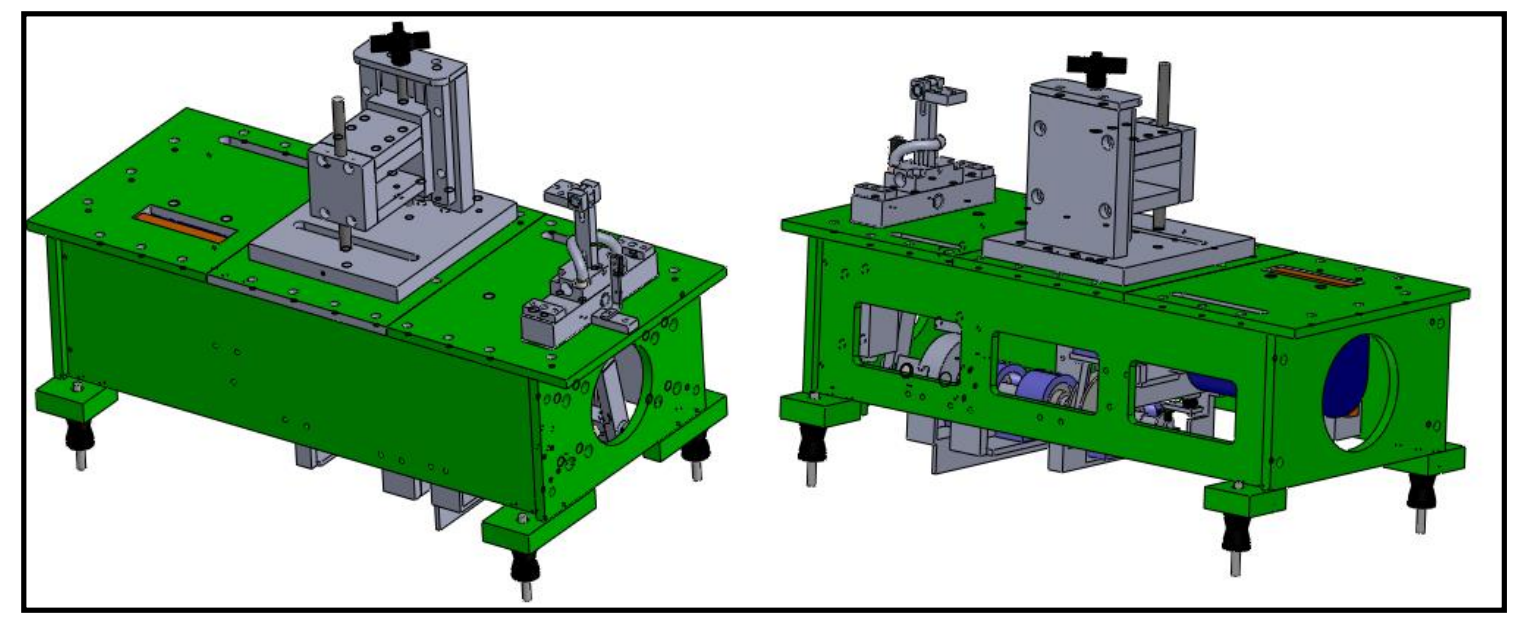

Figura 7: Modelamento completo da máquina em dois ângulos diferentes.

A maioria das peças da máquina é constituída dos aços baixo carbono ABNT 1020 e médio carbono ABNT 1045, sendo o primeiro destinado majoritariamente à parte estrutural da máquina e o segundo à parte dinâmica, como eixos e pinos. Esses aços foram adquiridos na forma de barras chatas, placas retangulares ou barras cilíndricas. As dimensões de aquisição foram maiores que as dimensões finais de cada peça, pois as peças necessitam de passar por posterior fabricação e acabamento, como será citado no tópico referente à fabricação e montagem da máquina.

Além dos aços ABNT 1020 e 1045, outros materiais foram utilizados na máquina e estes foram citados em cada subconjunto da máquina citado anteriormente. Cantoneiras de aço foram utilizadas como apoios aos mancais que sustentam a parte dinâmica da máquina. Para absorver e/ou minimizar vibrações, entre o motor e a estrutura metálica responsável por sua fixação, foi inserido um bloco de material polimérico e nos pés da mesa foram inseridos coxins de borracha que isolam a máquina da mesa.

$\mathrm{O}$ equipamento mais utilizado para a fabricação das peças foi um centro de usinagem, o qual permite a realização de diversas operações de usinagem, principalmente o fresamento e a furação. $\mathrm{O}$ equipamento possibilita a fabricação de peças garantindo a correta geometria das peças usinadas graças ao seu comando nu- 
mérico computadorizado. As peças cilíndricas da máquina de fadiga como os eixos, buchas e pinos foram usinadas em um torno convencional. Além do torneamento, o equipamento também possibilita que sejam realizadas outras operações, como a furação e o rosqueamento concêntricos.

Depois de fabricadas individualmente, cada peça deve ser fixada às demais, formando os subconjuntos e a máquina completa. As montagens das peças ocorreram de diferentes maneiras dependendo da necessidade de permitir uma possível desmontagem futura, a facilidade na montagem e o custo da montagem, desde que não comprometessem a rigidez da máquina. A união de peças ocorreu predominantemente por meio de parafusos de diferentes geometrias, o que possibilita que a desmontagem seja feita de maneira rápida e simples. Algumas outras montagens ocorreram em menor proporção com outros recursos diferentes do aparafusamento, como por exemplo, a soldagem e a interferência entre peças.

\subsection{Limitações}

A máquina em questão foi projetada para atender às necessidades de ensaios de fadiga por flexão, sendo este o único tipo de ensaio possível de se realizar. Os corpos de prova podem ser de diferentes materiais conforme necessidade, entretanto, a geometria do corpo de prova deve possuir suas extremidades planas com furos para permitir a sua fixação à máquina.

O comprimento e espessura dos corpos de prova são limitados pelo dimensionamento e posicionamento dos elementos mecânicos responsáveis pela fixação deste corpo de prova. Deste modo, a máquina admite corpos de prova com comprimentos variando aproximadamente de $110 \mathrm{~mm}$ até $402 \mathrm{~mm}$.

As características do corpo de prova e a amplitude da flecha não devem exigir esforços superiores ao que o motor consegue fornecer. Deste modo, apesar da redução utilizada, as tensões utilizadas nos ensaios não devem exigir um torque superior a $0,9 \mathrm{kgfm}$ disponibilizado pelo motor em conjunto com o sistema de redução utilizado.

O motor elétrico possui rotação nominal de $3330 \mathrm{rpm}$, entretanto, a rotação pode ser variada de 100 até $3330 \mathrm{rpm}$ através do inversor de frequência de frequência utilizado. A faixa de rotação recomendada segundo o manual do fabricante do motor é de $2800 \mathrm{rpm}$.

Como a máquina realiza movimentos rotativos e lineares, é extremamente importante estar atento à lubrificação de mancais, guias e eixos para que a máquina realize seu trabalho adequadamente e tenha maior durabilidade. Outros pontos da máquina devem ser verificados sempre: correia, rolamento do pino do volante, aperto dos parafusos, ruído e vibrações excessivos.

\section{RESULTADOS}

Testes preliminares da máquina para ensaio de fadiga por flexão foram realizados para confirmar se o equipamento foi projetado e construído corretamente. Para isso, foram usinados corpos de prova para serem ensaiados na máquina sob diferentes tensões e os resultados coletados foram inseridos em um gráfico de tensão versus número de ciclos. A máquina pronta para a realização dos testes é apresentada na Figura 8.

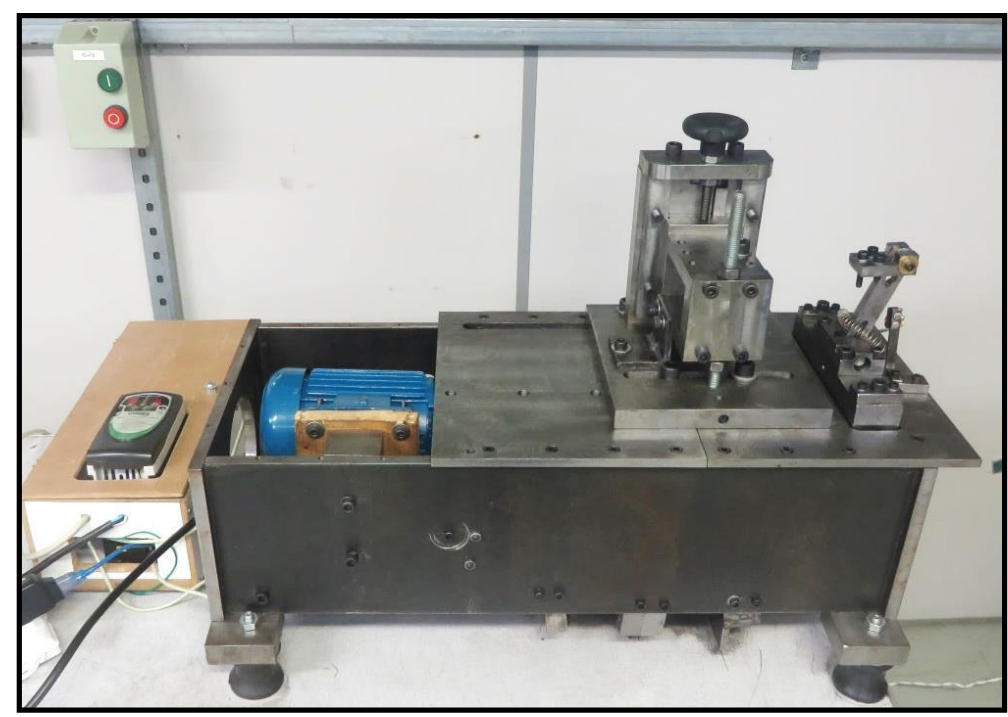

Figura 8: Máquina para ensaio de fadiga por flexão. 
A Figura 9 apresenta uma imagem de um dos corpos de prova utilizado nos ensaios com as principais dimensões. No total, sete amostras de aço baixo carbono ABNT 1020 foram usinadas e ensaiadas. As tabelas 1 e 2 apresentam, respectivamente, valores típicos de composição e de propriedades mecânicas do aço baixo carbono ABNT 1020. O material foi adquirido no formato de barras chatas com 31,75 mm de largura, 6,35 $\mathrm{mm}$ de espessura e $500 \mathrm{~mm}$ de comprimento. Todos os corpos de prova passaram pelo mesmo processo de fabricação, mantendo-se constante os parâmetros de corte para evitar uma variação nas características superficiais dos corpos de prova. Após fabricação dos corpos de prova, estes foram submetidos aos ensaios. A Figura 10 apresenta a fixação do corpo de prova antes do ensaio (A) e o corpo de prova após o ensaio (B).

Tabela 1: Composição química típica dos aços ABNT 1020.

\begin{tabular}{l|l|l|l|l|l}
\hline CARBONO & MANGANES & SILÍCIO & ENXOFRE & FÓSFORO & FERRO \\
\hline $0,20 \%$ & $0,45 \%$ & $\leq 0,20 \%$ & $\leq 0,05 \%$ & $\leq 0,03 \%$ & Balanceado \\
\hline
\end{tabular}

Tabela 2: Propriedades mecânicas típicas do aço baixo carbono ABNT 1020 [16].

\begin{tabular}{l|l|l}
\hline PROPRIEDADE & DIMENSÃO & UNIDADE \\
\hline Tensão de ruptura & $440 \times 10^{6}$ & pascal $(\mathrm{Pa})$ \\
\hline Limite de escoamento & $326,9 \times 10^{6}$ & pascal $(\mathrm{Pa})$ \\
\hline Tensão última & $544,49 \times 10^{6}$ & pascal $(\mathrm{Pa})$ \\
\hline
\end{tabular}

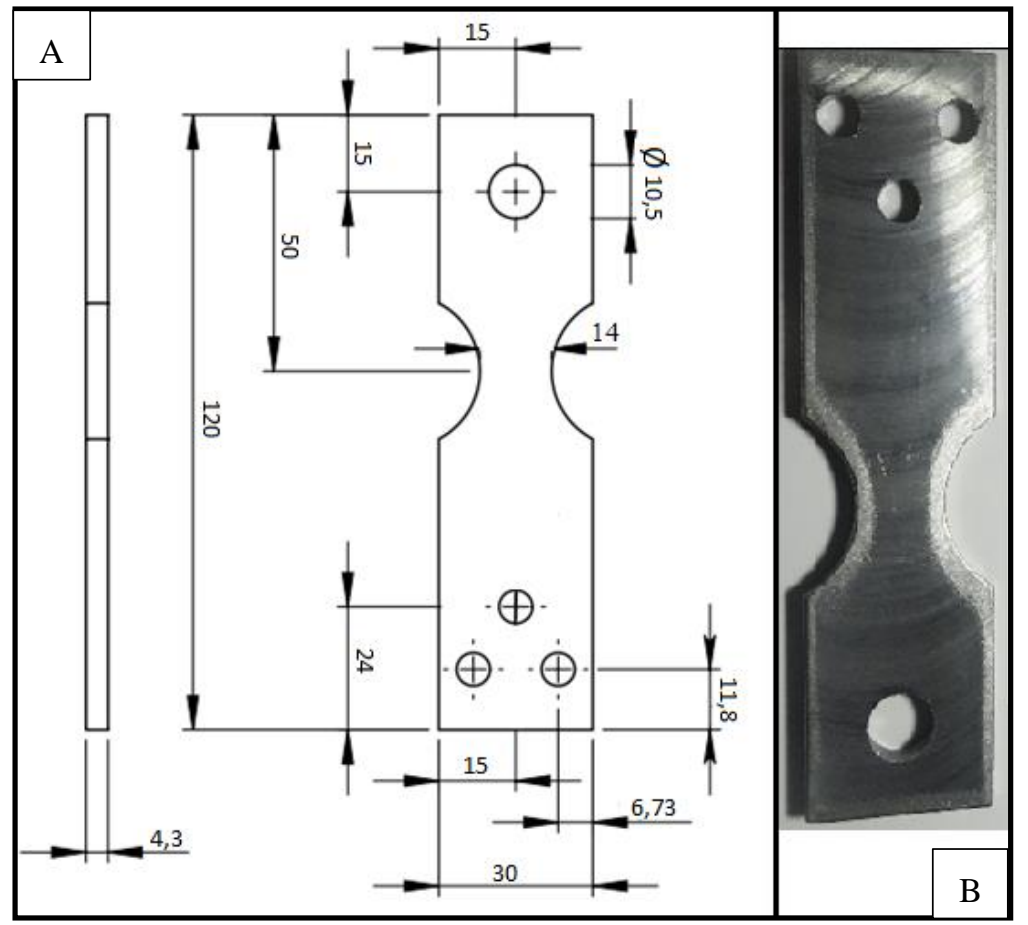

Figura 9: Corpo de prova para testes preliminares da máquina: (A) dimensionamento do corpo de prova; (B) imagem de um dos corpos de prova utilizados. 


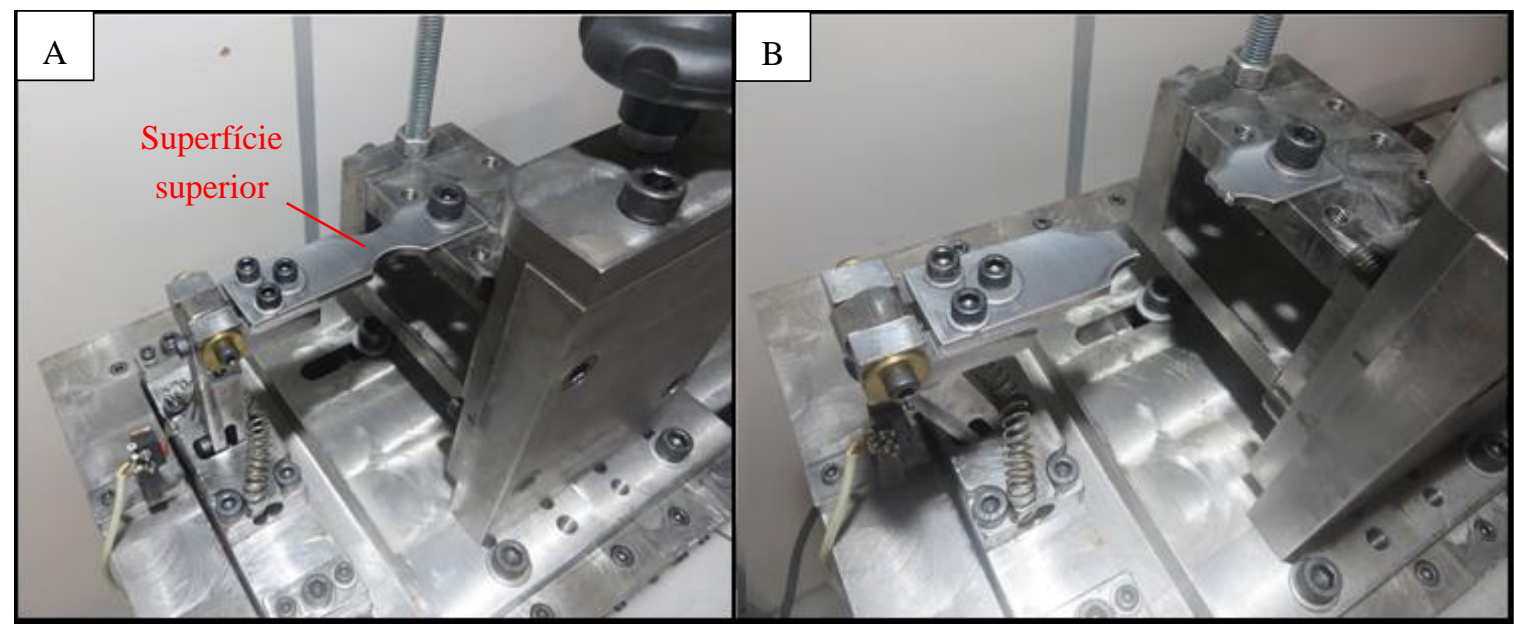

Figura 10: Imagem antes (A) e após (B) um ensaio de fadiga da máquina.

Antes da realização dos ensaios de fadiga, os corpos de prova foram submetidos a uma avaliação de rugosidade no perfilômetro HOMMELWERKE T4000 ajustado para uma velocidade de varredura de $1 \mathrm{~mm} / \mathrm{s}$ e passo de varredura de $0,4 \mathrm{~mm}$. A área analisada foi de 10 × $12 \mathrm{~mm}$ situada na região crítica do corpo de prova, onde é esperada a falha por fadiga. Cada corpo de prova foi analisado nas superfícies superior (Figura 10) e inferior. Para a região superior dos corpos de prova, o valor de desvio médio aritmético ( $\mathrm{Ra}$ ) observado foi $0,479 \mu \mathrm{m}$ com desvio padrão foi de $0,161 \mu \mathrm{m}$ e para a região inferior o valor de $\mathrm{Ra} 0,617 \mu \mathrm{m}$ com desvio padrão de $0,203 \mu \mathrm{m}$.

Os resultados dos ensaios são apresentados na Figura 11 e o método de cálculo da tensão aplicada encontra-se no Apêndice I. Nota-se que o comportamento do material é semelhante à curva de Wöhler clássica mostrada na Figura 1, ou seja, o número de ciclos para fadiga aumenta à medida que a tensão é reduzida. Foi considerado que o material possuía vida infinita de fadiga quando o número de ciclos para a tensão aplicada fosse superior a $10^{6}$, deste modo, dois ensaios realizados foram encerrados mesmo antes da ruptura do material, registrando vida infinita de fadiga para as tensões de 44 e $95 \mathrm{MPa}$.

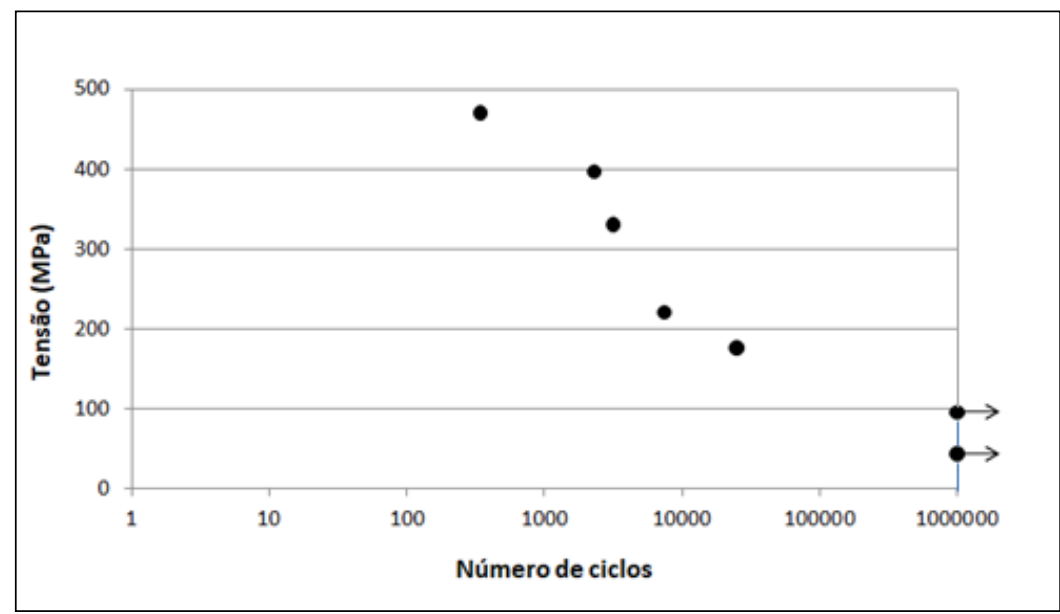

Figura 11: Gráfico tensão versus número de ciclos dos ensaios realizados.

\section{CONCLUSÕES}

Uma máquina para ensaio de fadiga por flexão foi projetada, fabricada e montada. O equipamento foi testado e funciona corretamente, estando apto para realizar ensaios de fadiga de corpos de prova de diferentes materiais e geometrias. A máquina foi desenvolvida em etapas, iniciada pela fase de projeto onde a mesma foi divida nos subconjuntos estrutural, dinâmico e de controle e coleta de dados. Cada subconjunto foi projetado e analisado utilizando softwares auxiliares antes de se passar para a fase seguinte que consistiu na fabricação de cada peça dos subconjuntos. Um sistema eletrônico com sensores e dispositivos foi utilizado para possibi- 
litar a contagem de ciclos, o início e encerramento dos ensaios e armazenamento dos principais dados de cada ensaio.

Após a construção da máquina, testes preliminares foram realizados e os resultados obtidos foram satisfatórios. Como resultado, foi gerado um gráfico de tensão versus número de ciclos até a fratura para valores de tensão escolhidos aleatoriamente, sendo que para valores acima de $10^{6}$ ciclos foi considerado que o material possui vida infinita de fadiga. Para se traçar a curva é necessário um número maior de ensaios com intervalos de tensões menores e mais regulares. Pode-se concluir que a região de vida infinita para o material ensaiado possui seu limite máximo entre as tensões de $176 \mathrm{MPa}$ e $95 \mathrm{MPa}$

\section{AGRADECIMENTOS}

Os autores agradecem ao Programa de Pós-Graduação em Engenharia Mecânica da Universidade Federal de Minas Gerais pelo apoio à realização deste projeto, aos professores Ana Maria G. Figueiredo e Gabriel O. Ribeiro, do Departamento de Engenharia de Estruturas da mesma universidade, pelas discussões acerca do projeto do equipamento e à empresa Voges (Caxias do Sul, RS), pelo fornecimento do motor elétrico e inversor de frequência usados neste trabalho.

\section{BIBLIOGRAFIA}

[1] CALLISTER Jr., W. D. Ciência e Engenharia de Materiais: Uma Introdução. 7 ed., Editora LTC, 2008. [2] ASKELAND, D. R., WRIGHT, W. J. Ciência e Engenharia dos Materiais., São Paulo, Cengage Learning, 2014.

[3] SMITH, W. F. Princípio de ciência e engenharia dos materiais. 3. ed., McGRW-HILL, 1998.

[4] COLLINS, J. A. Failure of Materials in Mechanical Design: Analysis, prediction, prevention. 2. ed., Estados Unidos: John Wiley \& Sons INC, 1993. ISBN 0-471-55891-5.

[5] SANTOS Jr., A. A. Sistemas mecânicos - Introdução e fadiga. Apostila do Departamento de Projetos Mecânicos, FEM - UNICAMP, 2002.

[6] HIBBELER, R. C. Resistência dos Materiais, 7 ed., Pearson Prentice Hall, 2010.

[7] ROSA, E. Análise de Resistência Mecânica: Mecânica da Fratura e Fadiga, Universidade Federal de Santa Catarina, Departamento de Engenharia Mecânica, Santa Catarina, 2002.

[8] ELLYIN, F. Fatigue Damage, Crack Growth and Life Prediction. 1. ed., Chapman \& Hall, 1997.

[9] LEMAIRE, J., DESMORAT, R. Engineering Damage Mechanics: Ductile, Creep, Fatigue and Brittle Failures, Springer, 2010.

[10] LEE, Y., PAN, J., HATHAWAY, R., et al., Fatigue testing and analysis: theory and practice, Elsevier Butterworth-Heinemann, 2005.

[11] FINE, M. E., CHUNG Y. Fatigue Failure in Metals. Departamento de Ciência e Engenharia dos Materiais, Universidade Northwestern, In: ASM Handbook, Fatigue and Fracture, vol 19, 1996.

[12] SCHIJVE, J. Fatigue of Structures and Materials. 2 ed., Springer, 2009.

[13] MILELlA, P. P. Fatigue and Corrosion in Metals, 1 ed., Itália, Springer, 2013.

[14] DIETER, G. E. Fundamental Structure-Property Relationships in Engineering Materials. Universidade Tecnológica Michigan. In: ASM Handbook, Materials Selection and Design, v. 20, 1997.

[15] GAUTAM, A., AJIT, K. P., SARKAR, P. K. "Fatigue Damage estimation through Continuum Damage Mechanics", In: 11th International Symposium on Plasticity and Impact Mechanics, Implast 2016, pp. 15671574, India.

[16] LACERDA, J.C., MARTINS, G.D., SIGNORETTI, V.T., et al., "Evolution of the surface roughness of a low carbono steel subjected to fatigue”, International Journal of Fatigue , v.102, pp. 143-148, May 2017.

[17] HAGHSHENAS, A., KHONSARI, M.M., "Damage Accumulation and Crack Initiation Detection Based on the Evolution of Surface Roughness Parameters", International Journal of Fatigue, October 2017, DOI: https://doi.org/10.1016/j.ijfatigue.2017.10.009.

[18] LAGES, M. S., Desenvolvimento de uma máquina para ensaio de fadiga por flexão, Tese de M. Sc., DEMEC/UFMG, Belo Horizonte, MG, Brasil, 2017. 


\section{APÊNDICE I - CÁLCULO DA TENSÃO APLICADA AO CORPO DE PROVA}

Considerando o engaste perfeito em uma das extremidades do corpo de prova e a outra extremidade submetida à flexão, o cálculo das tensões aplicadas em cada corpo de prova segue os princípios dos cálculos para flexões em vigas simples. O cálculo é feito para o ensaio com flecha de 1,3 mm, entretanto, os cálculos podem ser utilizados para determinar as tensões para os outros ensaios.

Dados de entrada:

Comprimento total do corpo: $120 \mathrm{~mm}$

Comprimento do corpo de prova do ponto engastado até a extremidade móvel (1): $108 \mathrm{~mm}$ Comprimento extremidade móvel até região de fratura (lf): 70

Largura menor do corpo de prova (b): $14 \mathrm{~mm}$

Espessura do corpo de prova (h): $4,3 \mathrm{~mm}$

Distância do centroide de área até a superfície do corpo de prova (y): 2,15 mm

Altura de flecha $(\delta): 1,3 \mathrm{~mm}$

Modulo de elasticidade aproximada: $205 \times 10^{3} \mathrm{~N} / \mathrm{mm}^{2}$

Momento de inércia do corpo de prova (I):

$$
I=\frac{b h^{3}}{12}=\frac{14 \times 4,3^{3}}{12}=92,758 \mathrm{~mm}^{4}
$$

Força aplicada no ensaio (F):

$$
F=\frac{3 E I \delta}{I^{3}}=\frac{3 \times 205 \times 10^{3} \times 92,758 \times 1,3}{108^{3}}=58,871 \mathrm{~N}
$$

Momento na região onde ocorre a fratura (M):

$$
M=F \times l f=58,871 \times 70=4120,97 \mathrm{Nmm}
$$

Tensão aplicada na região onde ocorre a fratura por fadiga $(\delta)$ :

$$
\sigma=\frac{M y}{I}=\frac{4120,97 \times 2,15}{92,758}=95,518 \mathrm{MPa}
$$

\section{ORCID}

Alexandre Mendes Abrão

Anderson Júnior dos Santos

Marcelo Araújo Câmara

Matheus da Silva Lages https://orcid.org/0000-0003-2015-4077

https://orcid.org/0000-0002-5285-3289

https://orcid.org/0000-0003-0617-9163

https://orcid.org/0000-0003-1529-8607 